УДК 338:012

08.00.00 Экономические науки

АКТУАЛЬНЫЕ ПРОБЛЕМЫ УПРАВЛЕНИЯ
АГРАРНЫМ СЕКТОРОМ НА
СОВРЕМЕННОМ ЭТАПЕ
ЭКОНОМИЧЕСКОГО РАЗВИТИЯ

Сергиенко Екатерина Геннадьевна

к.э.н., старший преподаватель

SPIN-код: 6290-9426

Author ID: 56583959100

Коршикова Марина Викторовна

к.э.н., старший преподаватель

SPIN-код: 7002-8973 Author ID: 618625

Чернобай Наталья Борисовна

к.э.н., доцент

SPIN-код: 7872-8770

Ставропольский государственный аграрный

университет, Ставрополь, Россия

Статья посвящена решению актуальной задачи определения на сегодняшний день роли агропромышленного комплекса России в экономической теории с учетом всемирной глобализации экономики. В ней рассматриваются производство сельского хозяйства, как развитый конкурентоспособный сельскохозяйственный сектор, являющийся залогом продовольственной безопасности существования страны. В работе проведен анализ факторов, влияющих на развитие сельского хозяйства, среди которых самыми важными являются низкая степень монополизации сельских товаропроизводителей по сравнению с другими отраслями экономики; высокий уровень капиталоемкости сельского хозяйства и низкая его рентабельность; диспаритет цен в

сельскохозяйственной отрасли; высокая конкуренция импорта. В статье представлены основные вопросы, требующие целенаправленного своевременного рассмотрения, такие как: вопросы о протекционистских мерах, направленных на помощь аграриям от федеральных агентств; роль страховых и лизинговых организаций в стимулировании аграриев в обновлении парка сельхозтехники; необходимость эффективной помощи региональных властей в продвижении программы импортозамещения; выявление и устранение «узких мест» в продвижении южнороссийского зерна на мировой рынок; разработка мер для решения иных проблем, сдерживающих развитие отрасли. Предложен ряд рациональных и эффективных мероприятий по решению основных вопросов управления аграрным сектором экономки

Ключевые слова: СЕЛЬСКОЕ ХОЗЯЙСТВО,
UDC 338:012

Economics

\section{ACTUAL PROBLEMS OF THE AGRARIAN SECTOR AT THE PRESENT STAGE OF ECONOMIC DEVELOPMENT}

\author{
Sergienko Ekaterina Gennadievna \\ Cand.Econ.Sci., senior lecturer \\ SPIN-code: 6290-9426 \\ Author ID: 56583959100 \\ Korshikova Marina Viktorovna \\ Cand.Econ.Sci., senior lecturer \\ SPIN-code: 7002-8973 Author ID: 618625 \\ Chernobay Natalia Borisovna \\ Cand.Econ.Sci., associate professor, SPIN- \\ code: $7872-8770$ \\ Stavropol State Agrarian University, \\ Stavropol, Russia
}

The article is devoted to solution of actual task of definition to the modern role of the agro-industrial complex of Russia in economic theory, in the globalized world economy. It deals with production in agriculture, as a developed competitive agricultural sector, which is the key to food security of the country's existence. In the work we present the analysis of factors affecting the development of agriculture, among which the most important are the low degree of monopolization of rural producers in comparison with other sectors of the economy; high level of capital intensity of agriculture and low profitability; disparity of prices in the agricultural sector; high level of competition imports.

The article presents the main issues to be focused for timely consideration, such as: questions about the protectionist measures to help the farmers from Federal agencies; the role of insurance and leasing organizations in encouraging farmers in replacing agricultural equipment; the need for effective assistance of regional authorities in the promotion of the import substitution program; the identification and elimination of "bottlenecks" in the promotion of South Russian grain on the world market; development of measures to solve other problems constraining the sector's development. We have also offered a number of rational and effective interventions for addressing key management issues of agricultural sector

Keywords: AGRICULTURE, AGRARIAN SECTOR, 
АГРАРНЫЙ СЕКТОР, ЗЕРНО, ПРОИЗВОДСТВО, $\quad$ GRAIN, PRODUCTION, FOOD SECURITY ПРОДОВОЛЬСТВЕННАЯ БЕЗОПАСНОСТЬ

Doi: 10.21515/1990-4665-127-019

Российское село играет особую роль для поступательного развития страны, тем самым создавая необходимость поддержки сельской экономики и сельскохозяйственной отрасли как стратегически важного сектора, обеспечивающего продовольственную безопасность [11].

В Российской Федерации сельские территории составляют около 90 $\%$ от всей территории страны, на них проживают 38 млн. россиян. Низкий уровень качества жизни в сельской местности, неразвитость социальной, коммунальной и транспортной инфраструктуры, недостаток рабочих мест, отсутствие возможности для самореализации - все это усиливает вымирание, отток, миграционные настроения трудоспособного сельского населения, особенно молодежи и с каждым днем сельчан становится все меньше и меньше. Бегство в города создает угрозы национальной и экономической безопасности страны, ведет к потере контроля над удаленными территориями, росту социальной напряженности и разрушению генофонда уникального культурного наследия. В настоящее время $37 \%$ сельских населенных пунктов полностью обезлюдели или в них проживают менее 10 человек [2, 5].

В связи с этим, решение проблем российского села и аграрного сектора, повышение его конкурентоспособности на мировом рынке, а также социальное развитие села являются стратегической целью политики государства, решением проблемы импортозамещения. Сельский труженик, фермер, житель малого города или поселка - это основа российской государственности. Практика показывает, что развитие крестьянских (фермерских) хозяйств, других малых форм хозяйствования на селе является не только эффективным средством роста производства 
сельскохозяйственной продукции, но и возрождения российского села [1, 7].

Производство зерна является основой обеспечения продовольствием миллионов людей на планете. Это один из стратегических секторов экономики многих стран, от устойчивого развития которого зависит их продовольственная безопасность. По состоянию на 2016 г. география экспорта российского зерна достигла 100 стран, а Россия входит в четверку лидирующих стран по производству и экспорту зерновых и площади пахотных земель [4].

Однако, несмотря на то, что южные регионы страны приносят основную часть зернового урожая страны, и рыночные цены на него достаточно высоки, южнороссийское зерно далеко не всегда побеждает на зарубежных тендерах, а производители не могут обеспечивать себя в нужном количестве ГСМ, удобрениями и обновлённой техникой $[3,8]$.

Особую роль в аграрной политике России занимает модернизация сельского хозяйства. Модернизация предусматривает переход к инновационной экономике, повышение ее конкурентоспособности. Таким образом, модернизация экономики является одним из важнейших приоритетов аграрной политики России на сегодняшний момент. Следует отметить, что проведение полномасштабной модернизации аграрного сектора потребует огромных инвестиций, но это крайне необходимо, так как основной целью модернизации является достижение высокой конкурентоспособности сельскохозяйственного сектора.

Для повышения конкурентоспособности сельскохозяйственной продукции необходимо реализовать стратегию инновационного развития аграрного сектора России на основе новых мировых реалий и принципов, и, прежде всего, необходимости резкого повышения конкурентоспособности отечественной сельскохозяйственной продукции, а также обеспечить прорыв на мировой рынок. Во многих европейских 
странах, США инновационную деятельность принято считать основой, инфраструктурой экономики, а главная роль в укреплении инновации в сельском хозяйстве принадлежит государству [8]. В связи с модернизацией аграрного сектора необходимо усилить роль государства в определении приоритетных направлений развития инвестиционной и инновационной деятельности в сельском хозяйстве [3].

Учитывая важность вышеизложенных проблем, Правительству Российской Федерации и Министерству сельского хозяйства Российской Федерации совместно с региональными властями необходимо разработать региональные целевые программы по развитию отдельных отраслей сельского хозяйства.

К основным вопросам, требующих целенаправленного своевременного рассмотрения, относятся:

- $\quad$ вопросы о протекционистских мерах, направленных на помощь аграриям от федеральных агентств;

- $\quad$ роль страховых и лизинговых организаций в стимулировании аграриев в обновлении парка сельхозтехники;

- $\quad$ необходимость эффективной помощи региональных властей в продвижении программы импортозамещения;

- выявление и устранение «узких мест» в продвижении южнороссийского зерна на мировой рынок;

- $\quad$ разработка мер для решения иных проблем, сдерживающих развитие отрасли.

В связи с вышеизложенным, необходимо провести следующие мероприятия [10]:

1. Правительству Российской Федерации:

1.1 Обеспечить всестороннюю, в том числе финансовую, государственную поддержку развития и функционирования зернового хозяйства на всех уровнях при равной доступности, что обеспечит 
возможность расширенного воспроизводства зерна и его реализацию на равных конкурентных условиях [18];

1.2 Создать и применять эффективную систему государственного регулирования рынка зерна, позволяющую неизбежно и своевременно применять, ослаблять или отменять регулирующие меры в зависимости от действия на конъюнктуру внешних и внутренних факторов [6];

1.3 Создать условия для роста рентабельности зернопроизводства;

1.4 Разработать и внедрить программу по техническому перевооружению сельхозпроизводителей в течение 3 лет на основе отечественного и импортного сельхозмашиностроения;

1.5 Обеспечить создание условий для развития производств комплектующих для сельскохозяйственной техники, как одного из основных факторов углубления степени локализации, предусмотрев выделение финансовых средств на эти цели в рамках государственной программы поддержки отрасли [12];

1.6 Провести улучшение транспортно-логистической инфраструктуры [11];

1.7 Продолжить совершенствование системы механизмов снижения рисков в растениеводстве, в том числе доработать федеральный закон о6 агростраховании;

1.8 В целях сохранения выращенного урожая предусмотреть выделение субсидий на реконструкцию и строение зерносушильных объектов;

1.9 Восстановить государственную систему сортосмены и сортообновления;

1.10 Обеспечить развитие зернового производства, что подразумевает разработку и освоение в производственных условиях передовой системы семеноводства, энергоресурсосберегающих и 
экологически безопасных технологий возделывания традиционных культур [13];

1.11 Осуществить систему мер по дооснащению и коренному техническому перевооружению материально-технической базы зернового сектора и перерабатывающих отраслей;

1.12 Проработать механизм субсидирования инвестиционных и краткосрочных кредитов, предусматривающий льготное кредитование сельскохозяйственных организаций, крестьянских (фермерских) хозяйств, сельскохозяйственных кооперативов по эффективной кредитной ставке не более $5 \%$ [15];

1.13 Учитывая сложившуюся в настоящее время на рынке ситуацию с неиспользуемыми землями, серьезной закредитованностью сельхозтоваропроизводителей и ограниченностью у них финансовых средств на проведение землеустроительных работ и оформление земли, отсутствие возможности залога земельных участков из земель сельскохозяйственного назначения, находящихся как в государственной (муниципальной), так и в долевой собственности, представляется целесообразным рассмотреть возможность создания Корпорации содействия вовлечению в сельскохозяйственный оборот неиспользуемых земель;

1.14 Поддержать рассмотрение возможности распространения патентной системы налогообложения на все виды сельскохозяйственной деятельности [14];

1.15 Поддержать мораторий на введение дополнительных неналоговых сборов для сельхозтоваропроизводителей до 2020 года.

2. Министерству сельского хозяйства Российской Федерации:

2.1 Поддержать создание в сети Интернет банк лучших проектов грантовой поддержки местных инициатив граждан, проживающих в сельской местности, реализованных в рамках Федеральной целевой 
программы «Устойчивое развитие сельских территорий на 2014-2017 годы и на период до 2020 года» в целях их широкой популяризации и продвижения;

2.2 Поддержать разработку нормативно-правового документа, обязывающего специалистов АПК не реже 1 раза в год проходить повышение квалификации, а работников, занятых в аграрной сфере и не имеющих профильного образования пройти профессиональную переподготовку [17];

2.3 Поддержать создание кадрового резерва ученых, специалистов и руководителей для предприятий агропромышленного комплекса региона и сельскохозяйственной науки.

3. Средствам массовой информации:

3.1 Поддерживать и развивать на федеральных и региональных телеи радиоканалах циклы передач, направленных на популяризацию аграрного образования, сельскохозяйственной науки и сельского образа жизни среди молодежи;

3.2 Усилить информационно-пропагандистскую работу по популяризации положительного имиджа работников агропромышленного комплекса на телевидении, радио, в Интернете, печатных СМИ [16].

Таким образом, аграрный сектор экономики в современных условиях требует развития новых институтов и методов регулирования сельского хозяйства России. Инновационные программы должны включать государственную финансовую поддержку, модернизацию материальнотехнической базы предприятий, развитие переработки продукции, повышение роли науки в развитии инновационного производства, совершенствования механизма развития агропромышленной интеграции, гибкую ценовую политику, стимулирование производства этой продукции на основе прямых закупок. Все выше перечисленное может повысить эффективность реализации предложенных направлений. [2]. Эти и другие 
меры позволят государству обеспечить интенсивное развитие сельскохозяйственного производства и повышения привлекательности отечественных и иностранных инвестиций в сельскохозяйственный сектор отечественной экономики.

В заключение хочется отметить, что данный момент у России есть все необходимые предпосылки для создания мощного агропромышенного комплекса, который не только перестанет быть дотационной часть российской экономики, но и будет одним из основных ее направлений, позволяющих полностью обеспечить продовольственную безопасность государства, предоставить большое количество рабочих мест и внесет огромный вклад в решение проблемы мирового продовольственного дефицита.

\section{Список литературы}

1. Baidakov A.N., Bannikova N.V., Voitsekhovskaya S.S. (2015) Identification of strategic alternatives in agribusiness // Modern Applied Science.

2. Baidakov A.N., Chernobay N.B., Nazarenko A.N., Zaporozhets D.V., Sergienko E.G. (2015) Methodical Bases for Developing Predictive Scenarios of Agribusiness // Asian Social Science. P. 9-18.

3. Банникова Н.В. (2004) Особенности стратегического планирования аграрного производства // Достижения науки и техники АПК. 2004. № 11. С. 15.

4. Банникова Н.В., Костюченко Т.Н., Ермакова Н.Ю. (2011) Методические подходы к разработке программ развития сельскохозяйственного производства // Экономика сельскохозяйственных и перерабатывающих предприятий. 2011. № 8. С. 2023.

5. Васютин, А. С., Лысенкова, Т. М. Формирование и развитие территориальных зерновых связей в Российской Федерации / А. С. Васютин, Т. И. Лысенкова. - М., 1998. - 220 с.

6. Вермель, Д. Ф. Вопросы размещения и специализации сельскохозяйственного производства в региональных системах ведения сельского хозяйства / Д. Ф. Вермель // Сб. науч. тр. / ВНИИ экономики сельского хозяйства, 1988. - Вып. 125. - С. 18-23.

7. Герасимов, А.Н., Громов, Ю.И., Левченко, С.А., Скребцова, Т.В., Кобозев, М.А. (2013) Моделирование и прогнозирование ключевых показателей социальноэкономического развития традиционно аграрных регионов // Журнал мировых прикладных наук. № 27 (10). С. 1282 - 1287

8. Гордеев, А. В. Актуальные проблемы развития сельского хозяйства Российской Федерации / А. В. Гордеев // Экономика сельскохозяйственных и перерабатывающих предприятий, 2005. - № 8. - С. 1-5.

9. Жигалов, А. Н. Организация зернового рынка в России : Учебник для вузов / А. Н. Жигалов // Междунар. академия информационных процессов и технологий. - М. : Хлебпродинформ. - 1996. - 409c. 
10. Золотарева, Е. Л., Векленко, В. И., Аверюшин, А. А. Органические удобрения важнейшее условие повышения устойчивости земледелия / Е. Л. Золотарева, В. И. Векленко, А. А. Аверюшин // Материалы международной научно-практической конференции - Ч. 3. - Курск: КГСХА, 2002 - С. 112-113.

11. Колосков, П. И. Климатический фактор сельского хозяйства и агроклиматическое районирование / П. И. Колосков. - Гидрометиздат, 1976 - 45 с.

12. Копенкин, Ю. И. Повышение устойчивости зернового производства путем оптимизации структуры посевных площадей / Ю. И. Копенкин // Системный анализ в разработке механизированных сельскохозяйственных технологий. Зерноград, 1984. - С. 88-95.

13. Кусакина О.Н. Многофункциональность сельского хозяйства как фактор развития сельских территорий / О.Н. Кусакина // Актуальные проблемы социальноэкономического развития региона сборник научных трудов по материалам Всероссийской научно-практической конференции. - 2016. - С. 137-140.

14. Малько, А. М. Качество семян важнейших сельскохозяйственных растений в Российской Федерации / А. М. Малько. - М.: ЗАО «Издательство ИКАР». - 2005. - 70 c.

15. Огарков, С. П. Причины кризиса в сельском хозяйстве и направления его оздоровления / С. П. Огарков // АПК: экономика, управление. - 2004. - №4. - С. 30-35.

16. Рено-Дженти, К., Бургос, С., Бенуа, М. (2014) Выбор наиболее представительных направлений технического управления в рамках различных методов управления: Использование виноградников в долине Луары для экологической и качественной оценки // Европейский журнал агрономии. № 56. - С. 19-36

17. Трухачев В.И., Банникова Н.В., Тельнова Н.Н. (2011) Стратегическое планирование в сельском хозяйстве // Теория и практика / Ставрополь, 2011.

18. Ши, К., Лин, Я., Чжан, Е., Ян, Х., Жан, Ж., (2013) Воздействие посева земли и мелиорации на климат и производства зерна в Северо-Восточном Китае через 30 лет / / Достижения в метеорологии. - 2013 - 853098.

\section{References}

1. Baidakov A.N., Bannikova N.V., Voitsekhovskaya S.S. (2015) Identification of strategic alternatives in agribusiness // Modern Applied Science.

2. Baidakov A.N., Chernobay N.B., Nazarenko A.N., Zaporozhets D.V., Sergienko E.G. (2015) Methodical Bases for Developing Predictive Scenarios of Agribusiness // Asian Social Science. P. 9-18.

3. Bannikova N.V. (2004) Osobennosti strategicheskogo planirovanija agrarnogo proizvodstva // Dostizhenija nauki i tehniki APK. 2004. № 11. S. 15.

4. Bannikova N.V., Kostjuchenko T.N., Ermakova N.Ju. (2011) Metodicheskie podhody $\mathrm{k}$ razrabotke programm razvitija sel'skohozjajstvennogo proizvodstva // Jekonomika sel'skohozjajstvennyh i pererabatyvajushhih predprijatij. 2011. № 8. S. 20-23.

5. Vasjutin, A. S., Lysenkova, T. M. Formirovanie i razvitie territorial'nyh zernovyh svjazej v Rossijskoj Federacii / A. S. Vasjutin, T. I. Lysenkova. - M., 1998. - 220 s.

6. Vermel', D. F. Voprosy razmeshhenija i specializacii sel'skohozjajstvennogo proizvodstva $\mathrm{v}$ regional'nyh sistemah vedenija sel'skogo hozjajstva / D. F. Vermel' // Sb. nauch. tr. / VNII jekonomiki sel'skogo hozjajstva, 1988. - Vyp. 125. - S. 18-23.

7. Gerasimov, A.N., Gromov, Ju.I., Levchenko, S.A., Skrebcova, T.V., Kobozev, M.A. (2013) Modelirovanie i prognozirovanie kljuchevyh pokazatelej social'no-jekonomicheskogo razvitija tradicionno agrarnyh regionov // Zhurnal mirovyh prikladnyh nauk. № 27 (10). S. $1282-1287$

8. Gordeev, A. V. Aktual'nye problemy razvitija sel'skogo hozjajstva Rossijskoj 
Federacii / A. V. Gordeev // Jekonomika sel'skohozjajstvennyh i pererabatyvajushhih predprijatij, 2005. - № 8. - S. 1-5.

9. Zhigalov, A. N. Organizacija zernovogo rynka v Rossii : Uchebnik dlja vuzov / A. N. Zhigalov // Mezhdunar. akademija informacionnyh processov i tehnologij. - M. : Hlebprodinform. - 1996. - 409s.

10. Zolotareva, E. L., Veklenko, V. I., Averjushin, A. A. Organicheskie udobrenija vazhnejshee uslovie povyshenija ustojchivosti zemledelija / E. L. Zolotareva, V. I. Veklenko, A. A. Averjushin // Materialy mezhdunarodnoj nauchno-prakticheskoj konferencii - Ch. 3. Kursk: KGSHA, 2002 - S. 112-113.

11. Koloskov, P. I. Klimaticheskij faktor sel'skogo hozjajstva i agroklimaticheskoe rajonirovanie / P. I. Koloskov. - Gidrometizdat, 1976 - 45 s.

12. Kopenkin, Ju. I. Povyshenie ustojchivosti zernovogo proizvodstva putem optimizacii struktury posevnyh ploshhadej / Ju. I. Kopenkin // Sistemnyj analiz v razrabotke mehanizirovannyh sel'skohozjajstvennyh tehnologij. Zernograd, 1984. - S. 88-95.

13. Kusakina O.N. Mnogofunkcional'nost' sel'skogo hozjajstva kak faktor razvitija sel'skih territorij / O.N. Kusakina // Aktual'nye problemy social'no-jekonomicheskogo razvitija regiona sbornik nauchnyh trudov po materialam Vserossijskoj nauchno-prakticheskoj konferencii. - 2016. - S. 137-140.

14. Mal'ko, A. M. Kachestvo semjan vazhnejshih sel'skohozjajstvennyh rastenij v Rossijskoj Federacii / A. M. Mal'ko. - M.: ZAO «Izdatel'stvo IKAR». - 2005. - 70 s.

15. Ogarkov, S. P. Prichiny krizisa v sel'skom hozjajstve i napravlenija ego ozdorovlenija / S. P. Ogarkov // APK: jekonomika, upravlenie. - 2004. - №4. - S. 30-35.

16. Reno-Dzhenti, K., Burgos, S., Benua, M. (2014) Vybor naibolee predstavitel'nyh napravlenij tehnicheskogo upravlenija $\mathrm{v}$ ramkah razlichnyh metodov upravlenija: Ispol'zovanie vinogradnikov $\mathrm{v}$ doline Luary dlja jekologicheskoj i kachestvennoj ocenki // Evropejskij zhurnal agronomii. № 56. - S. 19-36

17. Truhachev V.I., Bannikova N.V., Tel'nova N.N. (2011) Strategicheskoe planirovanie v sel'skom hozjajstve // Teorija i praktika / Stavropol', 2011.

18. Shi, K., Lin, Ja., Chzhan, E., Jan, H., Zhan, Zh., (2013) Vozdejstvie poseva zemli i melioracii na klimat i proizvodstva zerna v Severo-Vostochnom Kitae cherez 30 let / / Dostizhenija v meteorologii. - 2013 - 853098. 